\title{
DETECTION AND DIFFERENTIATION OF HUMAN PROTOZOAN PARASITES IN STOOL SPECIMENS BY USING MULTIPLEX ALLELE SPECIFIC POLYMERASE CHAIN REACTION (MAS-PCR) \\ In New Damietta City, Egypt \\ Khaled Abd El-Aziz Mohammad
}

Department of Parasitology, Faculty of medicine (Damietta), Al-Azhar University, New Damietta City, Egypt.

\begin{abstract}
Enteric protozoa continue to be the most commonly encountered parasitic diseases causing significant morbidity and mortality in developing regions of the world affecting millions of people. This study assessed the use of Multiplex Allele Specific Polymerase Chain Reaction (MAS-PCR) assay and microscopy for detection and identification of common pathogenic protozoan parasites in New Damietta city of North Delta region, Egypt. Between Jun 2013 until Sept 2013, fresh stool samples were obtained from 249 patients up to 65 years of age attending the internal clinic of the Damietta University Hospital and those visiting their general practitioner (GP) of outpatient clinics because of gastrointestinal symptoms. Stool samples collected was preserved at -200C for DNA extraction whilst the remaining was preserved in sodium acetate-acetic acid formalin and concentrated using the formol-ether technique for microscopic examination. DNA extracts were analyzed with the multiplex allele specific Polymerase Chain Reaction (MAS-PCR) for pathogenic protozoan parasites. The diagnostic results obtained using a multiplex allele specific PCR for the detection of histolytica/dispar, G. lamblia and C. parvum/C. hominis were compared with these obtained by routine microscopy of faecal samples from patients. 69 samples were positive by MAS-PCR assays , 9 cases of $G$. intestinalis infection, 34 cases of D. fragilis infection, 3 cases of E. histolytica infection, 17 cases E.dispar and 6 cases of Cryptosporidium infection in the clinical samples. By microscopy, only 32 samples were positive for one or more of the enteric protozoa, 5 cases of $G$. intestinalis infection, 9cases of $D$. fragilis infection, 13 cases of $E$. histolytica infection, and 1 cases of Cryptosporidium infection in the clinical samples. However, there are no cases of E.dispar observed. Mixed infections were detected in 4 samples. The sensitivities varied from $58 \%$ for D. fragilis to $47 \%$ for E. histolytica, $35 \%$ for Giardia, and $30 \%$ for Cryptosporidium, while the specificities also varied from $97 \%$ for E. histolytica to $99 \%$ for D. fragilis and $100 \%$ for E.dispar. No cross-reactivity was detected in stool samples containing various other bacterial, viral, and protozoan species. This present study showed relatively high rates of protozoa infections in the study patients. The study has also demonstrated that the multiplex real time PCR assay was more sensitive compared to microscopy in the diagnosis of the intestinal protozoa parasites and thus, molecular methods must be considered the diagnostic methods of choice for enteric protozoan parasites.

Keywords: Human intestinal protozoa, Stool specimens, Microscopy, Multiplex Allele Specific Polymerase Chain Reaction (MAS-PCR), Diagnosis.
\end{abstract}

\section{INTRODUCTION}

$\mathrm{E}$ nteric protozoa continue to be the most commonly encountered parasitic diseases and to cause significant morbidity and mortality throughout developing regions of the world, affecting millions of people each year ${ }^{(36 \& 60)}$. Numerous protozoa inhabit the gastro-intestinal tract of humans. The majority of these protozoa are non-pathogenic, or only result in mild disease. Some of these organisms can cause severe disease under certain circumstances. For example, Giardia lamblia can cause severe acute diarrhea which may lead to a chronic diarrhea and nutritional disorders; Entamoeba histolytica can become a highly virulent and invasive organism that causes a potentially lethal systemic disease ${ }^{(36)}$.Apicomplexa and microsporidia species can cause severe and lifethreatening diarrhea in AIDS patients and other immunocompromised individuals ${ }^{(61)}$.Intestinal protozoa are transmitted by the fecal-oral route and exhibit life cycles consisting of a cyst stage and a trophozoite stage. The cysts consist of a resistant wall and are excreted in the feces. The cyst wall functions to protect the organism from desiccation in the external environment. Unhygienic conditions promote transmission of most protozoa (32\&51). Laboratory diagnosis of these protozoan parasites for many years has relied on the traditional microscopic examination of stool samples. This is regarded as the gold standard when performed by an experienced and a highly skilled microscopist However, the sensitivity and specificity of the microscopic technique has been found to be rather low $^{(44 \& 30)}$. It is laborious and requires long professional training and may present false positive and negative results. The principal limitation of this method is its inability to differentiate closely related species and heterogeneity within species, as it is often difficult to differentiate cysts of the pathogenic from the non-pathogenic intestinal 
protozoa $^{(11)}$.To optimize parasite detection and identification, other diagnostic methods have been developed such as the Immunofluorescence (IF), Enzyme-linked immunosorbent assay (ELISA), culture and subsequent differentiation by isoenzyme analysis and the Polymerase Chain Reaction (PCR) .These have been introduced as alternative methods that are more sensitive and specific. These applications however, also have limitations ${ }^{(56)}$. Recently, more specific and sensitive alternative PCR methods have been introduced for all of these parasitic infections ${ }^{(45 \& 58)}$. However, the incorporation in a routine diagnostic laboratory of these parasite-specific methods for diagnosis of each of the respective infections is time-consuming and increases the costs of a stool examination. Traditionally parasites have been identified by simple microscopy, serologic and PCR methods ${ }^{(25 \& 48)}$. The traditional PCR protocols require further processing of the amplicon, which is timeconsuming and prone to false-positive results due to possible cross-contamination In an effort to improve on the PCR protocol, the multiplex allele specific PCR has been developed which is able to circumvent the problems associated with the traditional PCR and the other detection methods. This method allows specific detection of the amplicon, discriminating between $E$. histolytica, $E$. dispar, G. lamblia, and C. parvum in a single assay by binding to one or two fluorescence-labeled probes during PCR. A Multiplex Allele Specific Polymerase Chain Reaction (MAS-PCR) was developed for the simultaneous detection of intestinal protozoa infections in stool samples, it is capable of detecting the minimum amounts of organisms required to cause disease and the presence of multiple protozoan species in a single clinical sample. This improves the diagnosis of parasitic diarrhoeal infection, hence patient management ${ }^{(66 \& 76)}$. The multiplex PCR also included an internal control to determine efficiency of the PCR and detect inhibition in the sample. The assay was performed on species-specific DNA controls and a range of well-defined stool samples, and it achieved 100 percent specificity and sensitivity. The use of this assay in a diagnostic laboratory would provide sensitive and specific diagnosis of the main parasitic infections and could improve patient management and infection control $^{(23)}$.Cryptosporidium is an important diarrhea-causing parasitic protozoan found in both humans and animals ${ }^{(1 \& 19)}$. Conventional methods for detecting Cryptosporidium oocysts in faecal specimens involve microscopic detection of oocysts using either a direct fluorescent antibody (DFA) assay with broadly reactive Cryptosporidium species antibodies or a modified acid-fast staining technique. However, neither of these methods can identify Cryptosporidium at the species level, and their diagnostic strength depends on the skills of the examiner ${ }^{(10 \& 64)}$.

monoclonal antibodies against Cryptosporidium antigens has been developed and successfully used; however, this method cannot identify Cryptosporidium at the species level, despite being practical as a screening method ${ }^{(26)}$.Various PCR formats have been employed to distinguish species of Cryptosporidium. PCR-based detection has been shown to be sensitive and specific for the detection of $C$. parvum in clinical specimens and environmental samples ${ }^{(4,40,62,73, \& 75)}$.PCR-RFLP and PCR followed by DNA sequencing analysis have been described as reliable approaches for the distinction of $C$. hominis from $C$. parvum (formerly known as $C$. parvum genotypes 1 and 2 , respectively) ${ }^{(37,52 \& 53)}$. Nevertheless, they are time-consuming and labourintensive, making them inadequate for a rapid diagnostic response during outbreak investigations. A Multiplex Allele Specific Polymerase Chain Reaction (MAS-PCR) with specific primers and probes represents an alternative to conventional PCR for increasing the speed of sample analysis while decreasing the potential risks for contamination of the laboratory environment with amplicons ${ }^{(23)}$. The causative agent of amebic colitis and liver abscess is E. histolytica ${ }^{(54)}$. The non pathogenic parasites $E$. dispar and $E$. moshkovskii are more common and identical in appearance to $E$. histolytica ${ }^{(29)}$. $E$. dispar and E. histolytica are morphologically identical and phylogenetically closely related ${ }^{(71)}$. Both E. histolytica and E. dispar are able to colonize humans but only $E$. histolytica is able to cause invasive disease (colitis and extraintestinal manifestations) ${ }^{(47)}$. Tissue destruction is not seen with $E$. dispar in vivo. Earlier a panel of researchers concluded that colonization with $E$. dispar has never been documented to cause invasive disease in humans therefore the parasite does not necessitate treatment ${ }^{(69)}$. Giardia is a binucleated flagellated protozoan and these parasites can be found in mammals and other animals, including reptiles and birds ${ }^{(41)} \cdot$ G. lamblia 
is the most commonly isolated intestinal parasite throughout the world. Prevalence rates of $20-40 \%$ are reported in developing countries, especially in children ${ }^{(20)}$.

There are two distinct genotypes of $G$. lamblia that infect humans, commonly referred to as assemblages $\mathrm{A}$ and $\mathrm{B}$. Molecular analyses have shown the genetic variance between the two assemblages to be greater than that used to delineate other species of protozoa. Dientamoeba fragilis is a pathogenic protozoan parasite that infects the mucosa of the large intestine, causing gastrointestinal disease in humans .Diagnosis of $D$. fragilis relies on direct visualization of the trophozoites in stained fixed fecal smears by light microscopy. D. fragilis may be difficult to distinguish from nonpathogenic

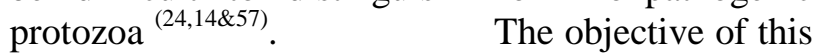
work is to detection and identification of common pathogenic protozoan parasites in New Damietta city of North Delta region in faecal samples of patients and to compare the prevalence of $E$. histolytica, $G$. lamblia and $C$. parvum using microscopy and multiplex allele specific PCR diagnostic methods. Also, to compare the test performance characteristics of microscopy and MAS-PCR to an expanded gold standard in the diagnosis of protozoa parasites in faecal samples of patients with gastrointestinal symptoms.

\section{Material and Methods}

Study site. The Damietta University Hospital is a major hospital serving New Damietta City and other parts of Damietta government of North Delta, Egypt. The hospital's coverage population is approximately 100,000 people. The laboratory department and molecular biology unit of the hospital offers diagnostic as well as research services.

Study population. All 175 symptomatic $(70.30 \%)$ and 74 a symptomatic $(29.70 \%)$ population up to 65 years old and permanently residing in New Damietta City who attend the internal Clinic of the hospital were included in this study and fulfilled the inclusion criteria i.e. Attending the internal clinic of the Damietta University Hospital visiting their general practitioner (GP) of outpatient clinics because of gastrointestinal symptoms and these who attended the clinic for their normal checkups. The age of the patients range from 0-65 years (median 33 years). The group examined contained significantly fewer children aged $<15$ years . Fecal specimens $(n=249)$ submitted to the Department of parasitology and molecular biology unit, Faculty of Medicine
(Damietta) at University Damietta Hospital. Specimens from outpatients were collected and submitted to the laboratory as a fresh specimen for investigation from Jun 2013 until Sept 2013, along with a portion mixed with sodium acetate-acetic acid-formalin (SAF)preservative ${ }^{(65)}$. Sampling. Labeled sterile containers with a collecting spoon were provided to all the cases and evaluation of clinical symptoms and sign was made at clinic

Sample processing. stool sample was collected from each case. The Fresh stool samples were transported to the laboratory immediately for analysis. Stool samples $(0.2 \mathrm{~g})$ were kept in a labeled $2.0 \mathrm{ml}$ Eppendorf tubes and frozen at $-20 \mathrm{oC}$ without preservative for molecular analysis. The remaining portions of the stools were preserved in Sodiumacetate acetic acid formalin solution (SAF) for microscopy and the formol-ether concentration method. The concentrate (sediments) was divided into two portions. One portion in a $15 \mathrm{ml}$ Falcon tube was stained with Lugol's iodine. Smear preparation of the other portion on clean dry $76 \mathrm{~mm}$ $\mathrm{x} 26 \mathrm{~mm}$ microscopy slide was stained with the modified Ziehl-Neelsen stain ${ }^{(23)}$. Microscopy. Unpreserved samples were investigated for trophozoites and cysts by microscopy of iodine-stained wet-mount preparations of a formalin-ether concentrate $^{(8)}$.Sodium acetate acetic acid formalinpreserved samples were first screened by iodinestained direct smears. Parasite-like structures were confirmed by microscopy of Modified ZiehlNeelsen staining for the detection of Cryptosporidium was performed and examined by oil immersion microscopy $(\times 1,000 \text { magnification })^{(46 \& 27)}$.

DNA extraction. DNA of up to $30 \mathrm{~kb}$ of Giardia lamblia, Cryptosporidium parvum, Entamoeba histolytica, Entamoeba dispar, Dientamoeba fragilis in the unpreserved stool samples were extracted and purified using the QIAamp DNA Stool mini kit (Qiagen, Hilden, Germany). The extraction was done according to the manufacturer's protocol and according to ${ }^{(58 \& 69)}$. In brief, $100 \mu \mathrm{L}$ of faecal suspension was added to $2 \mathrm{~mL}$ of lysis buffer and incubated at room temperature for $10 \mathrm{~min}$, after which an internal control (Phocin herpes virus-1 (PhHV-1); c. 6000 copies/sample) and $50 \mu \mathrm{L}$ of magnetic silica particles were added. The mixture was mixed and incubated for $10 \mathrm{~min}$ at room temperature. After centrifugation for $2 \mathrm{~min}$ at 1500 
$g$, the supernatant was removed by aspiration and the pellet of silica-nucleic acid complexes was resuspended and washed in three washing buffers. Each washing step was conducted for 30 second on step 1 of the miniMAG instrument, with the exception of wash buffer 3 (15 s on step 1), after which the fluid was removed by aspiration. DNA was eluted in $100 \mu \mathrm{L}$ of elution buffer for $5 \mathrm{~min}$ at $60^{\circ} \mathrm{C}$ on a thermo shaker (Eppendorf, Hamburg, Germany) at $1400 \mathrm{rpm}$. The extracted DNA was stored at $-20^{\circ} \mathrm{C}$.

MAS-

PCR. Multiplex Allele Specific Polymerase Chain Reaction PCR assay was performed on DNA eluates from all the stool samples using the Corbett Rotor Gene 6000 (Corbett life sciences, Australia) from the high-copy-number, ribosomal DNA-containing Amoeba, Giardia, D. fragilis and Cryptosporidium episomes with the following specific primers (Widmer et al.,2000).E.histolytica,Ehd239F(5'ATTGTCGTGG CATCCTAACTCA3'), Ehd88R(5'GCGGACGGCT CATTATAACA3'), andhisto(VIC5'TCATTGAATGAATTGGCCATTT-3'-nonfluor; G. intestinalis, Giardia-80F (5'GACGGCTCAGGACAACGGTT3'), Giardia127R( 5'TTGCCAGCGGTGTCCG3'); Cryptosporidiumsp p., $\mathrm{CrF}\left(5^{\prime} \mathrm{CGCTTCTCTAGCCTTTCATGA3}{ }^{\prime}\right), \mathrm{CrR}($ 5'CTTCACGTGTGTTTGCCAAT3'), andCrypto(Te xasRed5'CCAATCACAGAATCATCAGAATCGA CTGGTATC-3'D.fragilis MAS-PCR was performed on all samplesDF3(5'GTTGAATACGTCCCTGCCCTTT 3')andDF4(5'TGATCCAATGATTTCACCGAGTC A-3') with the following changes to the reaction conditions; $10 \mathrm{~min}$ at $95^{\circ} \mathrm{C}$, followed by 40 cycles of $95^{\circ} \mathrm{C}$ for $15 \mathrm{~s}$ and $60^{\circ} \mathrm{C}$ for $60 \mathrm{~s}$. Oligos were designed from the region of maximum mismatch in the $18 \mathrm{~S}$ rRNA and ITS-2. The following primers were used to differentiate $E$. histolytica from $E$. dispar. E. histolytica specificprimerswere:Eh5AGAGAAGCATTGTTTC TAGATCTG-3(18S)

Eh 2 5-TTAATTATTAGACAAAGCCT-3(18S)Eh 3 5-TTATTGGTCTGGTCTGTC-3(ITS-2) $E$. dispar specific primers were:Ed 15GAAGAAACATTGTTTCTAAATCCA3(18S)Ed25CTACCTATTAGACATAGCCT3(18S)3 5-TTTATTAACTCACTTATA-3(ITS2).To directly demonstrate the authenticity of the $E$. dispar DNA , PCR amplification was carried out with species-specific primers. The sequence of $18 \mathrm{~S}$ rDNA and ITS1 and 2 of E. dispar is known
(Novati et al 1996; Som et al 2000).Amplification conditions were: denaturation at $94^{\circ} \mathrm{C}$ for $1 \mathrm{~min}$, annealing at $45^{\circ} \mathrm{C}$ for $E$. histolytica specific primersand $40^{\circ} \mathrm{C}$ for $E$. dispar specific primers, followed by extension at $72^{\circ} \mathrm{C}$ for $1 \mathrm{~min}$. The amplification was carried outfor 30 cycles in a DNA Thermal cycler (MJ Research,USA) PCR was performed in $25-\mu \mathrm{L}$ volumes containing PCR buffer, $5 \mathrm{mM} \mathrm{MgCl}_{2}, 2.5 \mu \mathrm{g}$ of bovine serum albumin, $12.5 \mathrm{pmol}$ of forward primer $(021 \mathrm{~F})$ annealing to both E. histolytica, E. dispar , 6.25 pmol of E. histolytica-specific reverse primer (CPHR) and 6.25 pmol of E. E. dispar C.specific reverse primer (CP-CR). Amplification comprised $15 \mathrm{~min}$ at $95^{\circ} \mathrm{C}$, followed by 45 cycles of $30 \mathrm{~s}$ at $94^{\circ} \mathrm{C}, 30 \mathrm{~s}$ at $58^{\circ} \mathrm{C}$ and $30 \mathrm{~s}$ at $72^{\circ} \mathrm{C}$, with a final extension for $5 \mathrm{~min}$ at $72^{\circ} \mathrm{C}$. Amplification was detected following electrophoresis in agarose $2 \%$ w/v gels stained with ethidium bromide.

PCR amplification and detection. Amplification reactions were performed in $25-\mu \mathrm{L}$ volumes containing PCR buffer (Hotstar mastermix; Qiagen, Venlo, The Netherlands), $5 \mathrm{mM} \mathrm{MgCl} 2,2.5 \mu \mathrm{g}$ of bovine serum albumin (Roche Diagnostics, Almere, The Netherlands), 3.125 pmol each of the $E$. histolytica- and $G$. lamblia-specific primers, 12.5 pmol of the Cryptosporidium-specific primer, 1.25 pmol of VIC-labelled MGB-Taqman probe (Applied Biosystems, Warrington, UK) for $E$. histolytica, 2.5 pmol of FAM-labelled doublelabelled probe (Biolegio, Nijmegen, The Netherlands) for G. lamblia, 2.5 pmol of Texas-redlabelled double-labelled probe for Cryptosporidium, and $5 \mu \mathrm{L}$ of template DNA. The PhHV-1-specific primers and probe set consisted of 3.75 pmol of each $\mathrm{PhHV}$-1-specific primer and 2.5 pmol of Cy5labelled double-labelled probe. Amplification comprised $15 \mathrm{~min}$ at $95^{\circ} \mathrm{C}$, followed by 50 cycles of $15 \mathrm{~s}$ at $95^{\circ} \mathrm{C}$ and $30 \mathrm{~s}$ at $60^{\circ} \mathrm{C}$. Amplification, detection and data analysis were performed using the I-cycler Real-Time PCR System and v.3.1.7050 software (Bio-Rad, Hercules, CA, USA).MT-PCR is a two-step assay using nested primer pairs in which the first step involves a highly multiplexed reaction to pre amplify multiple targets for between 15 and 20 cycles. These are then aliquoted into individual reaction tubes containing nested specific PCR primers as templates for the second-step reaction, which is performed using a liquid-handling robotics system provided by AusDiagnostics Pty. Ltd. (Sydney, Australia) For MT-PCR, the following items were placed on the deck of the 
liquid-handling system: a strip tube containing step 1 multiplexed primers was placed in the thermal cycler; a gene disc containing lyophilized step 2 primers was placed in a loading block; and oil (for covering PCR mixtures), master mix, and water tubes (all supplied in a kit form) were placed in a reagent block. The samples were directly added to the strip tube in the thermal cycler. A software template for the reaction was then selected, and all operations for performing the step 1 multiplexed pre amplification, dilution, The gene disc was then hermetically sealed in a heat sealer, and step 2 amplification was carried out in a Rotor-Gene RG6000 thermal cycler. At the end of step 2, the presence or absence of each target was automatically called using a software routine

\section{Results}

More than seventy percent $(70.30 \%)$ of the cases who provide stool samples were symptomatic. The ages of study cases ranged from 5 months to 65 years. The mean ages of the symptomatic and
(AusDiagnostics Pty. Ltd.) that compared the melting temperature of the product with expected values and checked the purity and quantity against predetermined threshold values, which were all manually verified. Master mix reagents and 72-well gene discs containing lyophilized primers were prepared and supplied by AusDia Control group .Control DNA extracted from an infected clinical sample was used as a positive control for the PCR assays. This control group underwent DNA extraction and MAS-PCR as described above.

Data analysis. Statistical analyses were performed using SPSS v.11.0.1 (SPSS Inc., Chicago, IL, USA).

asymptomatic were 33 years. Socioeconomic and clinical characteristics of study cases were shown in (Table 1).

Table 1: Socioeconomic and clinical characteristics of study cases.

\begin{tabular}{|c|c|c|c|c|c|c|c|c|c|}
\hline \multicolumn{2}{|c|}{$\begin{array}{l}\text { Socioeconomic } \\
\text { and health } \\
\text { care behavior } \\
\text { No. }(\%)\end{array}$} & \multicolumn{2}{|c|}{$\begin{array}{c}\text { Housing \& } \\
\text { Waste disposal } \\
\text { No. }(\%)\end{array}$} & \multicolumn{2}{|c|}{$\begin{array}{c}\text { Water supply \& } \\
\text { water contact } \\
\text { No. }(\%)\end{array}$} & \multicolumn{2}{|c|}{$\begin{array}{l}\text { Clinical } \\
\text { symptoms } \\
\text { No. }(\%)\end{array}$} & \multicolumn{2}{|c|}{$\begin{array}{c}\text { Stool consistency } \\
\text { No. }(\%)\end{array}$} \\
\hline Low & $\begin{array}{c}105 \\
(42.3)\end{array}$ & $\begin{array}{l}\text { Modern } \\
\text { building }\end{array}$ & $\begin{array}{c}219 \\
(87.9 \\
) \\
\end{array}$ & Piped & $\begin{array}{c}235 \\
(94.3)\end{array}$ & Anemia & $\begin{array}{c}19 \\
(7.6)\end{array}$ & Firm & $\begin{array}{c}90 \\
(36.1)\end{array}$ \\
\hline $\begin{array}{l}\text { Moderat } \\
\mathrm{e}\end{array}$ & $\begin{array}{c}90 \\
(36.1)\end{array}$ & $\begin{array}{l}\text { Primitiv } \\
\text { building }\end{array}$ & $\begin{array}{c}21 \\
(8.4)\end{array}$ & $\begin{array}{l}\text { River } \\
\text { Nile }\end{array}$ & $\begin{array}{c}45 \\
(18.7)\end{array}$ & $\begin{array}{c}\text { Diarrhea } \\
\text { Abdomin } \\
\text { al pain }\end{array}$ & $\begin{array}{c}78 \\
(31.3)\end{array}$ & Loose & $\begin{array}{c}66 \\
(26.5)\end{array}$ \\
\hline High & $\begin{array}{c}24 \\
(9.6)\end{array}$ & $\begin{array}{l}\text { Sewage } \\
\text { disposal }\end{array}$ & $\begin{array}{c}8 \\
(3.2)\end{array}$ & $\begin{array}{c}\text { Shallow } \\
\text { wells }\end{array}$ & $\begin{array}{c}19 \\
(7.6)\end{array}$ & $\begin{array}{c}\text { Nausea } \\
\& \\
\text { Vomiting }\end{array}$ & $\begin{array}{c}62 \\
(24.8)\end{array}$ & Mucoid & $\begin{array}{c}78 \\
(31.3)\end{array}$ \\
\hline $\begin{array}{c}\text { consulta } \\
\text { tion for } \\
\text { treatme- } \\
\text { nt }\end{array}$ & $\begin{array}{c}30 \\
(12.4)\end{array}$ & $\begin{array}{c}\text { Well } \\
\text { with } \\
\text { chamber } \\
\text { disposal }\end{array}$ & $\begin{array}{c}0 \\
(0.0)\end{array}$ & $\begin{array}{l}\text { Deep } \\
\text { wells }\end{array}$ & $\begin{array}{c}0 \\
(0.0)\end{array}$ & $\begin{array}{l}\text { Headach } \\
\text { e, fever, } \\
\text { fatigue, } \\
\text { pallor \& } \\
\text { Weight } \\
\text { loss }\end{array}$ & $\begin{array}{c}90 \\
(36.1)\end{array}$ & $\begin{array}{l}\text { Blood } \\
\text { stained }\end{array}$ & $\begin{array}{c}15 \\
(6.2)\end{array}$ \\
\hline
\end{tabular}

A total of $69 / 249$ samples(table $3 \& 4$ ) were positive by MAS-PCR assays detected 9 cases of $G$. intestinalis infection, 34 cases of $D$. fragilis infection, 3 cases of E. histolytica infection, 17 cases E.dispar and 6 cases of Cryptosporidium sp. infection in the clinical samples. MAS-PCR showed $100 \%$ sensitivity and specificity. With microscopy, only $32 / 249$ samples(table $2 \& 4$ )were positive for one or more of the enteric protozoa. Microscopy detected only 5 cases of $G$. intestinalis infection, 9 cases of $D$. fragilis infection, 13 cases of E. histolytica infection and 5 cases of Cryptosporidium sp. Mixed infections of pathogenic and non-pathogenic protozoa, Entamoeba coli,Entamoeba hartmani, Endolimax nana, were detected in 4 samples. However, there is no casas of E.dispar observed. It should be

noted that microscopy cannot differentiate the nonpathogenic, morphologically identical E. dispar from the pathogenic E. histolytica. Out of the 13 
microscopy-positive E. histolytica samples, compared to the PCR methods, only 3were true $E$. histolytica positives . When microscopy was compared to molecular method, the sensitivities varied from $58 \%$ for $D$. fragilis to $47 \%$ for $E$. histolytica, $35 \%$ for Giardia, and $30 \%$ for Cryptosporidium, while the specificities also varied from $97 \%$ for $E$. histolytica to $99 \%$ for $D$. fragilis and $100 \%$ for E.dispar. None of the control samples run by MAS-PCR produced a product. No crossreactivity was seen with the other organisms. A total of 249 fecal samples results included in the study were summarized in Table 4.

Table 2: Infection rate of protozoa in study cases by microscopy

\begin{tabular}{|c|c|c|c|c|}
\hline Parasites & $\begin{array}{c}\text { Total } \\
\mathbf{N}=\mathbf{2 4 9} \\
(\%)\end{array}$ & $\begin{array}{cc}\text { Symptomatic } & \mathbf{N} \\
=175 & \mathrm{n} \\
(\%) & \end{array}$ & $\begin{array}{c}\text { Asymptomati } \mathbf{N}=\mathbf{7 4} \\
\mathrm{n}(\%)\end{array}$ & P value \\
\hline $\begin{array}{l}\text { Entamoeba } \\
\text { histolytica/ dispar }\end{array}$ & $13(5.2)$ & $3(1.8)$ & $10(13.6)$ & $<0.097$ \\
\hline Giardia lamblia & $5(2.0)$ & $3(1.8)$ & $2(2.7)$ & $<0.001$ \\
\hline $\begin{array}{l}\text { Cryptosporidium } \\
\text { species }\end{array}$ & $5(2.0)$ & $4(2.3)$ & $1(1.4)$ & $<0.999$ \\
\hline Dientamoeba.fragilis & $9(3.7)$ & $5(2.9)$ & $4(5.4)$ & $<0.996$ \\
\hline
\end{tabular}

Table 3: Infection rate of protozoa in study cases by MAS-PCR

\begin{tabular}{|c|c|c|c|c|}
\hline Parasites & $\begin{array}{c}\text { Total } \\
\mathbf{N}=\mathbf{2 4 9} \\
(\%)\end{array}$ & $\begin{array}{cc}\text { Symptomatic } & \mathbf{N} \\
=175 & \mathrm{n} \\
(\%) & \end{array}$ & $\begin{array}{c}\text { Asymptomati } \mathbf{N}=\mathbf{7 4} \\
\mathrm{n}(\%)\end{array}$ & P value \\
\hline $\begin{array}{l}\text { Entamoeba } \\
\text { histolytica/ dispar }\end{array}$ & $20(8.0)$ & $3(1.8)$ & $17(22.9)$ & $<0.0001$ \\
\hline Giardia lamblia & $9(3.7)$ & $7(4.0)$ & $2(2.7)$ & $<0.001$ \\
\hline $\begin{array}{l}\text { Cryptosporidium } \\
\text { species }\end{array}$ & $6(2.4)$ & $3(1.8)$ & $3(4.1)$ & $<0.969$ \\
\hline Dientamoeba.fragilis & $34(13.7)$ & $23(13.1)$ & $11(14.9)$ & $<0.997$ \\
\hline
\end{tabular}


Table 4: summarized results included in the study

\begin{tabular}{|c|c|c|c|}
\hline \multirow[t]{2}{*}{ Parasites } & \multirow[b]{2}{*}{ Total $N=69$} & \multicolumn{2}{|l|}{ Microscopy } \\
\hline & & n TotalN=32 & $\mathrm{n}(\%)$ \\
\hline Entamoeba histolytica & $3(1.2)$ & $13(5.2)$ & \\
\hline Giardia intestinalis & $9(3.6)$ & $5(2.0)$ & \\
\hline Cryptosporidium sp. & $6(2.4)$ & $5(2.0)$ & \\
\hline Entamoeba dispar & $17(6.9)$ & $0(0.0)$ & \\
\hline Dientamoeba fragilis & $34(13.6)$ & $9(3.6)$ & \\
\hline Mixed Infection & $0(0.0)$ & $4(1.8)$ & \\
\hline
\end{tabular}

Primers were designed from regions of maximum sequence divergence between $E$. histolytica and $E$. dispar. Primer sequences are given in $18 \mathrm{~S}$ rDNA and ITS-2 is shown in figure 1 . The primer pair $(1+$ 3 ) in which one primer was derived from $18 \mathrm{~S}$ rDNA and the second from ITS-2 amplified the expected $1.29 \mathrm{~kb}$ fragment when the E. histolytica-specific primer was used with E. histolytica DNA but not with E. dispar DNA. Similarly, the E. disparspecific primer pair amplified the $1.29 \mathrm{~kb}$ fragment only from $E$. dispar DNA (figure 1A). Since the $E$.

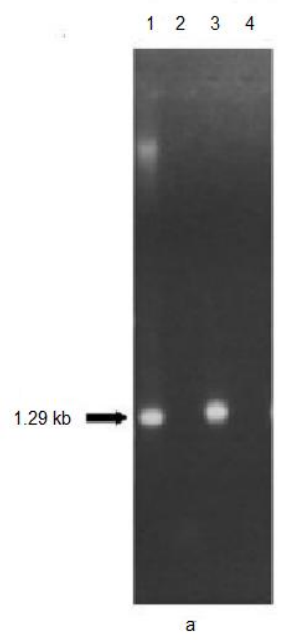

dispar DNA used in this study showed absolutely no amplification with the E. histolytica primer pair (figure 1A, lane 4), the possibility of any contamination was ruled out. The cloned EcoRI fragments of $E$. dispar rDNA were also tested for amplification with $E$. histolytica-specific and $E$. dispar-specific primer pairs derived from $18 \mathrm{~S}$ rDNA (primer pairs $1+2$ ). Both fragments amplified the expected 600 bp band only with the $E$. dispar-specific primer pairs (figure 1B).

Figure1. PCR amplification using species-specific primer pairs. The location of primers (Eh1, 2, 3 and Ed1, 2, 3 ) in the $18 \mathrm{~S}$ rDNA and ITS-2 is shown in the top panel. (A) PCR amplification of total genomic DNA of $E$. histolytica (lanes1 and 2) and E. dispar (lanes 3 and 4) with E. histolytica-specific primer pairs - Eh1 and Eh3 (lanes 1 and 4) and E. dispar-specific primer pairs - Ed1 and Ed3 (lanes 2 and 3). (B) PCR amplification of cloned EcoRI fragments of E. dispar rDNA - Ed (lanes 1 and 2) and Ed (lanes 3 and 4) with E. dispar-specific primer pairs - Ed1and Ed2 (lanes 1 and 3) and E. histolytica-specific primer pairs - Eh1 and Eh2 (lanes 2 and 4). Amplified products were separated by electrophoresis through $1 \%$ agarose gels for $6 \mathrm{~h}$ at $0 \square 8 \mathrm{~V} / \mathrm{cm}$. Sizes of amplified fragments are indicated. 


\section{DISCUSSION}

E. histolytica, G. intestinalis, Cryptosporidium, and $D$. fragilis are the four most important and commonly occurring diarrhea-causing parasitic protozoa $^{(63)}$. Therefore, it is essential that correct diagnosis be made, as all four protozoa can be successfully treated with a range of antiprotozoal drugs ${ }^{(31)}$.Infection with these parasites is rare, but its high morbidity and, in particular, mortality make accurate diagnosis crucial ${ }^{(6)}$.The Multiplex Allele Specific Polymerase Chain Reaction (MAS-PCR) assay for the detection of Cryptosporidium, Dientamoeba, E. histolytica/dispar, and G. intestinalis presented here provides an additional diagnostic tool for the rapid, sensitive, and specific detection of these enteric protozoa ${ }^{(23 \& 66)}$. The intestinal parasite with the highest prevalence in Delta region is D. fragilis followed by Entamoeba histolytica , ,Giardia lamblia $^{(16 \& 50)}$.About $40-50$ million people develop clinical amoebiasis each year, resulting on up to 100 000 deaths $^{(72)}$. In the present study a total of 13(5.2\%) Entamoeba histolytica/dispar prevalence was observed by microscopy but Entamoeba histolytica and Entamoeba dispar-specific DNA amplification using the multiplex allele specific polymerase chain reaction identified only $3(1.2 \%)$ $E$. histolytica cases and revealed a considerably higher prevalence of Entamoeba dispar 17(9.6\%). This observation compares well with results obtained in a similar study conducted in northern Ghana by ${ }^{(68 \& 70)}$, that showed a high prevalence $(9.8 \%)$ of $E$. histolyticaldispar complex by microscopy and $8.8 \%$ of Entamoeba dispar but only one case of Entamoeba histolytica by PCR. These results agree with Samuel Ekuban ${ }^{(15)}$ in North District of the Ashanti Region. In consonance with other studies ${ }^{(33)}$. This study showed a high prevalence of Giardia lamblia in asymptomatic cases. This suggests that Giardia lamblia infection either presents sub-clinically or the protozoa have limited pathogenicity. Analysis of 722 faecal DNA samples by Hove et al., ${ }^{(24 \& 31)}$ in the Netherland revealed that a prevalence rate of $9.3 \%$ of $G$. lamblia by PCR, as compared to $5.7 \%$ by microscopy. From a total of 480 patients and apparently healthy Egyptian selected, the prevalence rate of G. lamblia infection detected by concentration-sedimentation method was $11.0 \%{ }^{(17 \& 26)} \quad$ The primers used in the current study were aimed at detecting Cryptosporidium parvum (type II). This is because $C$. parvum is known to infect almost all mammals, including humans, and is a major pathogen of calves. Humans are infected with $C$. parvum in a zoonotic cycle ${ }^{(28)}$. In this study $5.6 \%$ by PCR of symptomatic and asymptomatic recruited cases were found to be infected with Cryptosporidium parvum. The overall prevalence of $4.4 \%$ and $4.9 \%$ by PCR and microscopy respectively. This study has demonstrated that $C$. parvum infection is predominantly common among children and is detected more frequently from symptomatic children than asymptomatic indicating that children with diarrhoea and/or vomiting are more likely to be infected with the protozoa ${ }^{(28 \& 45)}$. This is consistent with a previous study in Egypt by Abdel-Messih et al., (2). However these findings contradict the findings of ${ }^{(21)}$ in Keny and ${ }^{(3)}$ in Accra who indicated that Cryptosporidium infections were highest among children and adult. Classically, diagnosis of Giardia, Cryptosporidium and E. histolytica infections is achieved by microscopical examination of faecal samples ${ }^{(22)}$.However, microscopy has several important disadvantages: (i) correct identification depends greatly on the experience and skills of the microscopist; (ii) sensitivity is low, and therefore examination of multiple samples is needed; (iii) E. histolytica cannot be differentiated from the non-pathogenic Entamoeba dispar simply on the basis of the morphology of cysts and small trophozoites; and (iv) in settings with relatively large numbers of negative results ${ }^{(66-70)}$.Although molecular methods such as PCR have proven to be highly sensitive and specific for the detection of E. histolytica/E. dispar, G. lamblia and C. parvum/C. hominis infections ${ }^{(40)}$, their use in routine diagnostic laboratories is still very limited ${ }^{(7 \& 34)}$. The introduction of molecular methods has been hindered by time-consuming methods for the isolation of DNA from faecal specimens and the presence of inhibitory substances in such samples ${ }^{(18,42 \& 43)}$. Furthermore, amplification of DNA was previously laborious and expensive, and cross-contamination among samples was a notorious problem. However, newly developed methods have greatly reduced these obstacles $^{(20 \& 67)}$.A multiplex PCR reduces labour time, reagent costs and the risk of crosscontamination, and offers the possibility of detecting multiple targets in a single multiplex reaction. A multiplex PCR has been described for the simultaneous detection of the three most important diarrhoea-causing parasites, i.e., $E$. 
histolytica, G. lamblia and C. parvum/C. hominis, and has demonstrated high sensitivity and specificity with species-specific DNA controls and a range of well-defined stool samples ${ }^{(66)}$.However, the role of this assay as a diagnostic tool in a routine clinical laboratory requires further evaluation with respect to large-scale screening and improved patient diagnosis ${ }^{(9 \& 35)}$.This study highlights the lack of sensitivity that conventional staining techniques that are commonly used in most diagnostic laboratories provide for the diagnosis of these infections. The sensitivity of microscopy is as less as $60 \%$ and confounded with misleading results due to misidentification of macrophages as trophozoites,(polymorphonuclearleukocytes) PMNs as cysts (particularly when lobed nuclei of PMNs break apart), and other Entamoeba species .It was also showed that the assay is the most sensitive method for differential detection of $E$. histolytica and $E$. dispar because it is able to detect as little as $0.2 \mathrm{pg}$ for E. histolytica and $2 \mathrm{pg}$ each for both $E$. dispar DNA, whereas a single round PCR assay can detect $9.5 \mathrm{pg}$ of $E$. dispar and $19 \mathrm{pg}$ of E. histolytica ${ }^{(68 \& 70)}$.The main purpose of detection and differentiation of $E$. histolytica species in stool samples is the detection of the causative agent of amoebic dysentery. We showed that this multiplex PCR assay was capable of detecting nearly all of $(17 / 20)$ the suspected E. histolytica cases and showed that some of them were actually positive for $E$. dispar, 17 cases of and only three cases of $E$. histolytica. The MAS- PCR was shown to possess a higher level of sensitivity (100\%) for the detection of E.dispar in feces. This shows that our MASPCR is highly sensitive, capable of detecting target DNA at a copy number that the conventional microscopy unable to detect, agreement with $^{(11,36 \times 60)}$.On the basis of MAS- PCR assay, the number of E. histolytica positive cases found in stool samples is about 3 times higher than E. dispar. This result clearly indicates that the method used in diagnosis of amoebiasis could significantly affect estimates of the actual number of Entamoeba infections in North Delta supports that E. dispar infection is, in general, much more common than $E$. histolytica coinceded with similar study in Netherlands by Hove ${ }^{(31)}$.Microscopy detected only $32 / 249$ positive samples compared to 69/249 for the MAS-PCR assay. Compared to both assays, the sensitivity of microscopy ranged from $38 \%$ for $D$. fragilis up to $56 \%$ for Cryptosporidium. Previous studies by ${ }^{(55)}$, have produced similar findings.
When comparing microscopy, conventional PCR, and PCR for the detection of D. fragilis, it was found that, compared to MAS-PCR, microscopy had a sensitivity of only $34 \%$; this is similar to the $38 \%$ found in this study ${ }^{(56)}$. Detection of the other parasite-specific DNAs has also been shown to be more sensitive than microscopy, as it has for Giardia infections, for Cryptosporidium infections, and for amoebic infection with E. histolytica- and $E$. dispar-specific ${ }^{(23 \& 49)}$. The present study revealed that significant numbers of $E$. dispar and Cryptosporidium infections remain undetected by microscopy in patients with gastrointestinal symptoms who consult their GP. Furthermore, the number of additional parasites detected with microscopy was shown to be limited in this population. Therefore, the introduction of MASPCR for the routine detection of diarrhoea-causing protozoa would improve the diagnostic efficiency of laboratories dealing with faecal samples from this patient group ${ }^{(5,23 \& 66)}$.The data indicate that the use of microscopy alone for general, routine parasitological diagnosis has limited diagnostic value. It appears that the rationale for developing and implementing molecular screening platforms, combined with microscopy-based and specialized analyses where appropriate ${ }^{(8,36 \& 59)}$.In both the clinical samples and control samples tested the MAS-PCR for the detection of Cryptosporidium, Dientamoeba, E. histolytica, and G. intestinalis achieved a sensitivity and specificity of $100 \%$ Compared to previously published MAS-PCR assays targeting ${ }^{(36 \& 38)}$. The same organisms, in all samples tested in which microscopy revealed the presence of Cryptosporidium, Dientamoeba, E. histolytica, and G. intestinalis, specific amplification was detected. However, MAS-PCR detected an additional 69positive samples (6 Cryptosporidium, 34 D. fragilis, 17 E. histolytica, 3 E.dispar and 9 Giardia). The assay also was found not to cross-react with various other viral, bacterial, and protozoal fecal pathogens. The four samples previously suspected as mixed infection cases of Entamoeba coli with E. histolytica and positive by our MAS-PCR assay were confirmed that they were E. coli infections. Therefore, further development of molecular diagnosis for detection of other nonpathogenic Entamoeba species commonly found in humans, such as E. coli and E. hartmanni, will lead to specific identification and provide the true prevalence of these amoebae in epidemiological studies $^{(12,13 \& 58)}$. Because of the excellent specificity 
and sensitivity of MAS-PCR in this study, we propose its application as an alternative tool in routine diagnosis and in epidemiological studies of intestinal parasites. This method will provide more accurate epidemiological data and a greater understanding of infections with these parasites in humans ${ }^{(38,39,76 \& 77)}$.In summary, Traditionally, microscopy has been the method of choice; however, for diagnosis of enteric protozoans, molecular methods are now considered the gold standard for diagnosis, given the excellent sensitivities and specificities achieved by molecular methods. Although PCR-based assays have been successfully used for all organisms, this assay to provide detection of the four different targets in one commercially available kit. This is study developed and evaluated a multiplex PCR (MAS-PCR) assay for the simultaneous detection and identification of Cryptosporidium, D. fragilis, E. histolytica, and Giardia in human fecal samples. In the future, the implementation of such multiplex assays will have a tremendous impact on routine diagnostic laboratories, as these parasite targets could be combined with both viral and bacterial causes of diarrhea. This would represent a major advance in the differential laboratory diagnosis of diarrheal diseases in general.

\section{REFERENCES}

1. Alyousefi, M. A. K. ; Mahdy, Y. A. L. ;Lim, L. X. and Mahmud R .(2010): First molecular characterization of Cryptosporidium in Yemen. Parasitology .140: 729- 734.

2. Abdel-Messih I.A., Wierzba T.F., Abu-Elyazeed R., Ibrahim A.F., Ahmed S.F., Kamal K., Sanders J. and Frenck R. (2005) Diarrhea associated with Cryptosporidium parvum among young children of the Nile River Delta in Egypt. J Trop Pediatr 51, 154-159.

3. Adjei A.A., Armah H., Rodrigues O., Renner L., Borketey P., Ayeh-Kumi P., Adiku T., Sifah E. and Lartey M. (2004) Cryptosporidium Spp., a frequent cause of diarrhea among children at the Korle-Bu Teaching Hospital, Accra, Ghana. Jpn J Infect Dis 57, 216-219.

4. Amar, C.; McLauchlin, J.; Pedraza-Diaz, S. and Nichols, G. L.(2001): Molecular epidemiological analysis of Cryptosporidium spp. in the United Kingdom: results of genotyping Cryptosporidium spp. in 1,705 fecal samples from humans and 105 fecal samples from livestock animals. J Clin Microbiol. 38:3984-3990.

5. Ash, L. and Orihel, T. (1987): Collection and preservation of feces.: a Guide to Laboratory
Procedures and Identification. Chicago: American Society of Clinical Pathologists.28:18.

6. Blessmann , J. ;Buss, H. and $\mathrm{Nu}, \mathrm{P}$. (2002): Real-time PCR for detection and differentiation of Entamoeba histolytica and Entamoeba dispar in fecal samples. J Clin Microbiol. 40: 44134417.

7. Boom, R.; Sol, C. and Weel, J. (2003): Detection and quantization of human cytomegalovirus DNA in faeces. J Virol Methods. 84: 1-14.

8. Bruijnesteijn, v.; Coppenraet, L.E.; Wallinga, J.A.; Ruijs, G.J.; Bruins, M.J. and Verweij J.J. (2009):Parasitological diagnosis combining an internally controlled real-time PCR assay for the detection of four protozoa in stool samples with a testing algorithm for microscopy. Clin. Microbiol. Infect. 15: 869-874.

9. Caccio, S.; Spano, F. and Pozio, E. (2001): Large sequence variation at two microsatellite loci among zoonotic (genotype C) isolates of Cryptosporidium parvum. Int $\mathrm{J}$ Parasitol .31: 1082-1086.

10. Casemore, D. P.; Armstrong, M. and Sands, R. L. (1985): Laboratory diagnosis of cryptosporidiosis. J Clin Pathol. 38: 1337-1341.

11. Chalmers R.M., Smith R., Elwin K., CliftonHad ley F.A., andGiles M.(2010):Epidemiology of anthroponotic and zoonotic human cryptosporidiosis in England and Wales, 20042006. Epidemiol. Infect. 12:1-13.

12. Clark ,C .G. and Diamond, L.S. (1997): Intraspecific variation and phylogenetic relationships in the genus Entamoeba as revealed by riboprinting. Journal of Eukaryotic Microbiology. 44(2):142-154.

13. Clark, C.G. and Diamond, L.S. (2000): The Laredo strain and other 'Entamoeba histolyticalike' amoebae are Entamoeba moshkovskii. Molecular and Biochemical Parasitology. 46(1):11-18.

14. Crotti, D. ; D'Annibale, M. L. ; Fonzo, G. ; Lalle, M. Caccio, S. M. and Pozio, E. (2005): Dientamoeba fragilis is more prevalent than Giardia duodenalis in children and adults attending a day care centre in Central Italy. Parasite 12:165-170.

15. Ekou, J.; Nakavuma, J.L.; Erume J. and Ocaido, M. (2012):PCR detection of Entamoeba histolytica in microscopically positive stool samples of hospital patients in Soroti ,Eastern Ughanda. A. J. Clin. Exper .Microbiol.14(1): 59

16. El Shazly, A.M.; Soltan, D.M.; El-Sheikha, H.M.; Sadek, G.S. and Morsy, A.T. (2007): Correlation of ELISA coproantigen and oocysts count to the severity of cryptosporidiosis 
parvum in children. J Egypt Soc Parasitol 37(1): $107-120$

17. El-Naggar S.M., El-Bahy M.M., Abd Elaziz J. and El-Dardiry M.A. (2006) Detection of protozoal parasites in the stools of diarrhoeic patients using different techniques. J Egypt Soc Parasitol 36, 7-22.

18. Espy, M.J. ; Uhl, J.R. and Sloan, L.M. (2003): Real-time PCR in clinical microbiology: applications for routine laboratory testing. Clin Microbiol Rev.19: 165-256.

19. Fayer, R. (2004): Cryptosporidium: a waterborne zoonotic parasite. Vet Parasitol. 126: $37-$ 56.

20. Fraser, D. (1994) Epidemiology of Giardia lamblia and Cryptosporidium infections in childhood. J Med Sci 30: 356-361.

21. Gatei, W.; Ashford, R. W.; Beeching, N. J.; Kamwati, S. K.; Greensill, J. and Hart, C. A. (2002):Cryptosporidium muris infection in an HIV-infected adult, Kenya. Emerg Infect Dis. 8: 204-206.

22. Ghosh, S.; Debnath, A.; De Sil; A.S.; Chattopadhyay; D.J.and Das, P. (2002): PCR detection of Giardia lamblia in stool: targeting intergenic spacer region of multicopy rRNA gene. Mol Cell Probes. 14: 181-189.

23. Giles, M.; Warhurst, D. and Webster, K. (2002): A multiplex allele specific polymerase chain reaction (MAS-PCR) on the dihydrofolate reductase gene for the detection of Cryptosporidium parvnm genotypes 1 and 2 . Parasitol. 125:35-44.

24. Girginkardesler, N. S. ;Coskun, I. ;Cuneyt, P. and Ertan, S. (1998): Dientamoeba fragilis, a neglected cause of diarrhoea, successfully treated with secnidazole. Clin. Microbiol. Infect. 9:110-113.

25. Gool, T.; Weijts, R.; Lommerse, E.and Mank, T.G. (2003): Triple Faeces Test: an effective tool for detection of intestinal parasites in routine clinical practice. Eur J Clin Microbiol Infect Dis. 22: 284-290.

26. Graczyk, T. K.; Cranfield, M. R. and Fayer, R. (1996): Evaluation of commercial enzyme immunoassay (EIA) and immunofluorescent antibody (FA) test kits for detection of Cryptosporidium oocysts of species other than Cryptosporidium parvum. Am J Trop Med Hyg .54: 274-279.

27. Hadfield, G.; Stephen, J.; Robinson, E. and Elwin, K. (2011):Detection and Differentiation of Cryptosporidium spp. in Human Clinical Samples by Use of Real-Time PCR. J Clin Microbiol. 49(3): 918-24.

28. Hashim A., Mulcahy G., Bourke B. and Clyne M. (2006) Interaction of Cryptosporidium hominis and Cryptosporidium parvum with primary human and bovine intestinal cells. Infect Immun 74, 99-107.

29. Haque, R., Ali ,K.M.; Clark, C.G.; Petri ,F. and WA, J.R. (1998): A case report of Entamoeba moshkovskii infection in a Bangladeshi child. Parasitology International. 47(3):201-202.

30. Haque, R.; Roy, S.; Kabir, M.; Stroup, S.E.; Mondal, D. and Houpt, E.R. (2005) Giardia assemblage A infection and diarrhea in Bangladesh. J Infect Dis. 192: 2171-2173.

31. Hove, R.T. (2007): Detection of diarrhoeacausing protozoa in general practice patients in The Netherlands by multiplex real-time PCR. Clin. Microbiol. Infect. 13: 1001-1007.

32. Kappus, K.D.; Lundgren, R.G.; Juranek, D.D.; Roberts, J.M. and Spencer, H.C. (1994): Intestinal parasitism in the United States: update on a continuing problem. The American Journal of Tropical Medicine and Hygiene. 50(6):705713.

33. Klaus R., Ignatius R., Weitzel T., Seidu-Korkor A., Anyidoho L., Saad E., Djie-Maletz A., Ziniel P., Amoo-Sakyi F., Danikuu F., Danour S., Otchwemah R.N., Schreier E., Bienzle U., Stark K. and Mockenhaupt F.P. (2007) Acute childhood diarrhoea in northern Ghana: epidemiological, clinical and microbiological characteristics BMC Infectious Diseases 7, 1471-2334.

34. Kohli, A.; Bushen, O.Y. and Pinkerton, R.C .(2008): Giardia duodenalis assemblage, clinical presentation and markers of intestinal inflammation in Brazilian children. Transactions of the Royal Society of Tropical Medicine and Hygiene. 102(7):718-725.

35. Lewthwaite, P.; Gill, G.V.; Hart, C.A. and Beeching, N.J. (2005): Gastrointestinal parasites in the immunocompromised. Curr Opin Infect Dis.18: $427-435$.

36. Lieshout, L. and Verweij, J.J. (2010): Newer diagnostic approaches to intestinal protozoa. Curr. Opin. Infect. Dis.23: 488-493.

37. McLauchlin, J.;Amar, C.; Pedraza-Diaz, S. and Nichols, G. L.(2000): Molecular epidemiological analysis of Cryptosporidium spp. in the United Kingdom: results of genotypingCryptosporidium spp. in 1,705 fecal samples from humans and 105 fecal samples from livestock animals. J Clin Microbiol. 38:3984-3990.

38. Monar, N. (2009): Diagnosis of parasitic diseases old and new approaches .Infectious diseases vol(1) no. 15

39. Morgan, U.; Weber, R.; Xiao, L.; Sulaiman, I.; Thompson, R. C.; Ndiritu, W.; Lal, A.; Moore, A. and Deplazes, P. (2000): Molecular characterization of Cryptosporidium isolates 
obtained from human immunodeficiency virusinfected individuals living in Switzerland, Kenya, and the United States. J Clin Microbiol. 38: 1180-1183.

40. Morgan, U.M.and Thompson, R.C.A. (1998): PCR detection of Cryptosporidium: the way forward?Parasitol Today.14: 241-245.

41. Naelah, A. ;Alyousefi, M. and Mahdy, R. M. A.(2010): Molecular characterization of Giardia duodenalis in Yemen. Experimental Parasitology 2013; 134: 141-147.

42. Ouattara, M.; Gue'ssan, N.A.; Yapi, A. and N'Goran, E.K. (2012): Prevalence and Spatial Distribution of Entamoeba histolytica/dispar andGiardia lamblia among School children in Agboville Area (Co^ te d'Ivoire). PLoS Negl TropDis. 4:1

43. Pedraza-Diaz, S.; Amar, C. and McLauchlin, J. (2000): The identification and characterisation of an unusual genotype of Cryptosporidium from human faeces as Cryptosporidium meleagridis. Microbiol Lett. 189: 189-194.

44. Petri, W.A.; Haque, R.; Lyerly D. and Vines, R.R. (2000): Estimating the impact of amebiasis on health. Parasitol Today. 16, 320-321.

45. Pieniazek, N. J.; Bornay-Llinares, F. J.;Slemenda, S. B.;da Silva, A. J.;Moura, I. N.; Arrowood, M. J.; Ditrich, O. and Addiss, D. G.(1999). New Cryptosporidium genotypes in HIV-infected persons. Emerg Infect Dis.5: 444449.

46. Robinson, G.(2010): Redescriptionof Cryptospo ridiumcuniculus(Apicomplexa: Cryptosporidiida ): morphology, biology and phylogeny. Int. J. Parasitol. 40:1539-1548.

47. Romano, N.; Fakhrurrazi A.; Yvonne, A.; Jamaiah, I. and Rohela, M.(2010): Differentiating Entamoeba histolytica, Entamoeba dispar and Entamoeba moshkovskii using nested polymerase chain reaction (PCR) in rural communities in Malaysia. Parasites and Vectors 5: 187.

48. Roy, S.; Kabir, M.; Mondal, D.; Ali, K.M.; Petri, W.A. and Haque, R. (2005): Real-timePCR assay for diagnosis of Entamoeba histolytica infection. Journal of Clinical Microbiology. 43(5):2168-2172.

49. Samie, A.; Bessong, P.O. and Obi, C.L. (2006): Cryptosporidium species: preliminary descriptions of the prevalence and genotype distribution among school children and hospital patients in the Venda region, Limpopo Province, South Africa. Experimental Parasitology. 114(4):314-322.

50. Samn, K. A. M. ; Samn, A. A. M. and Abou ElNour, M. F. (2012): A survey of Giardia and Cryptosporidium spp. in Rural and Urban community in North Delta, Egypt. New York Science Journal .5(3):49-54.

51. Singh, A.; Houpt, E and Petri, W.A. (2009): Rapid diagnosis of intestinal parasitic protozoa, with a focus on Entamoeba histolytica. Interdiscip Perspect Infect Dis .5:47-90.

52. Spano, F.; Putignani, L.;Guida, S. and Crisanti, A. (1998).Cryptosporidium parvum: PCR-RFLP analysis of the TRAP-C1 (thrombospondinrelated adhesive protein of Cryptosporidium-1) gene discriminates between two alleles differentially associated with parasite isolates of animal and human origin. Exp Parasitol. 90: 195-198.

53. Spano, F.; Putignani, L.;McLauchlin, J.; Casemore, D. P. and Crisanti, A. (1997). PCRRFLP analysis of the Cryptosporidium oocyst wall protein (COWP) gene discriminates between C. wrairi and $C$. parvum, and between $C$. parvum isolates of human and animal origin. FEMS Microbiol Lett.150: 209217.

54. Stanley, S.L. ; Jackson, T.F.; Foster, L. and Singh, S. (1998): Longitudinal study of the antibody response to recombinant Entamoeba histolytica antigens in patients with amebic liver abscess. The American Journal of Tropical Medicine and Hygiene. 58(4):414-416.

55. Stark, D. J.; Barratt, T.; Roberts, D.; Marriott, J. and Ellis, J. (2010): Comparison of microscopy, two xenic culture techniques, conventional and real-time PCR for the detection of Dientamoeba fragilis in clinical stool samples. Eur. J. Clin. Microbiol. Infect. Dis. 29:411-416.

56. Stark, D. N. ;Beebe, D. ;Marriott, J. ;Ellis, and Harkness, J. (2006): Evaluation of three diagnostic methods, including real-time PCR, for detection of Dientamoeba fragilis in stool specimens. J. Clin. Microbiol. 44:232-235.

57. Stark, D.; Al-Qassab, S. E.; Barratt, J. L. N.; Stanley, K.; Roberts, T.; Marriott, J.; Harkness, D. and Ellis, J. T. (2011): Evaluation of Multiplex Tandem Real-Time PCR for Detection of Cryptosporidium spp. Dientamoeba fragilis, Entamoeba histolytica, and Giardia intestinalis in Clinical Stool Samples. J Clin Microbiol. 49(1): 257-262.

58. Stensvold, C.R. (2013):Blastocystis :genetic diversity ,molecular methods and epidemiology Tropical Parasitology . vol(3) no.11

59. Stensvold, C.R.; Lebbad, M. d. and Verweij J.J. (2011): The impact of genetic diversity in protozoa on molecular diagnostics. Trends Parasitol.27: 53-58.

60. Stensvold,R.C. and Nielsen,H.V. (2012):Comparison of microscopy and PCR for detection of intestinal parasites in Danish patients supports an incentive for molecular 
screening platforms. J Clin Microbiol. 50(2):540-1.

61. Stephen, J.; Hadfield, G.; Robinson, E. and Elwin, K. (2011):Detection and Differentiation of Cryptosporidium spp. in Human Clinical Samples by Use of Real-Time PCR. J Clin Microbiol. 49(3): 918-24.

62. Sturbaum, G. D.; Reed, C.; Hoover, P. J.; Jost, B. H.; Marshall, M. M. and Sterling, C. R. (2001): Species-specific, nested PCRrestriction fragment length polymorphism detection of single Cryptosporidium parvum oocysts. Appl Environ Microbiol .67:26652668.

63. Svenungsson, B.; Lagergren, A. and Ekwall, E. (2000): Enteropathogens in adult patients with diarrhea and healthy control subjects: a 1-year prospective study in a Swedish clinic for infectious diseases. Clinical Infectious Diseases. 30(5):770-778.

64. Tanyuksel, M. and Petri, W.A. (2003): Laboratory diagnosis of amebiasis. Clinical Microbiology Reviews. 16(4):713-729.

65. Troll, H.; Marti ,H. and Weiss, N. (1997): Simple differential detection of Entamoeba histolytica and Entamoeba dispar in fresh stool specimens by sodium acetate-acetic acidformalin concentration and PCR. Journal of Clinical Microbiology. 35(7):1701-1705.

66. Verweij , J.J., Roy, A. and Templeton K.(2004): Simultaneous detection of Entamoeba histolytica, Giardia lamblia and Cryptosporidium parvum in fecal samples using multiplex real-time PCR. J Clin Microbiol. 3: 1220-1223.

67. Verweij, J.J.; Blotkamp, J.;Brienen, E.A.T.;Aguirre, A. and Polderman, A.M. (2000): Polymerase chain reaction for differentiation of Entamoeba histolytica and Entamoeba dispar cysts on DNA isolated from faeces with spin columns. Eur J Clin Microbiol Infect Dis.5: 358-361.

68. Verweij, J.J.; Oostvogel, F.;Brienen, E.A.;Nang-Beifubah, A., Ziem, J.and Polderman, A.M. (2003a): Short communication: prevalence of Entamoeba histolytica and Entamoeba dispar in northern Ghana. Trop Med Int Health. 8: 1153-1156.

69. Verweij, J.J.; Polderman, A.M. and Clark, C. (2001): Genetic variation among human isolates of uninucleated cyst-producing Entamoeba species. Journal of Clinical Microbiology. 39(4):1644-1646.

70. Verweij, J.J.; Schinkel, J.; Laeijendecker ,D. ;Van Rooyen ,M.A.A.; Van Lieshout, L. and Polderman, A.M. (2003b): Real-time PCR for the detection of Giardia lamblia. Mol Cell Probes. 17: 223-225.

71. Visser, L.G.; Verweij, J.J.; Esbroeck, M.; Edeling, W.M.; Clerinx, J. and Polderman, A.M. (2006): Diagnostic methods for differentiation of Entamoeba histolytica and Entamoeba dispar in carriers: performance and clinical implications in a non-endemic setting. International Journal of Medical Microbiology. 96(6):397-403.

72. W H O (2010): Working to overcome the global impact of neglected tropical diseases. First WHO report on neglected tropical diseases. $172 \mathrm{p}$.

73. Webster, K. A.; Smith, H. V.; Giles, M.; Dawson, L. and Robertson, L. J. (1996): Detection of Cryptosporidium parvum oocysts in faeces: comparison of conventional coproscopical methods and the polymerase chain reaction. Vet Parasitol. 61:513.

74. Widmer, G.; Akiyoshi, D.; Buckholt, M. A.; Feng, X.; Rich, S. M.; Deary, K. M. ;Bowman, C. A.; Xu, P. and Wang, Y. (2000): Animal propagation and genomic survey of a genotype 1 isolate of Cryptosporidium parvum. Mol Biochem Parasitol .108 : 187-197.

75. Xiao, L.; Alderisio, K.; Limor, J.; Royer, M. and Lal, A. A. (2000): Identification of species and sources of Cryptosporidium oocysts in storm waters with a small-subunit rRNA-based diagnostic and genotyping tool. Appl Environ Microbiol. 66: 5492-5498.

76. Xiao, L.; Fayer, R.; Ryan, U.and Upton, S. J. (2004): Cryptosporidium taxonomy: recent advances and implications for public health. Clin Microbiol Rev. 17: 72-97.

77. Xiao, L.;Bern, C.;Limor, J.;Sulaiman, I.; Roberts, J.;Checkley, W.;Cabrera, L.; Gilman, R. H. and Lal, A. A. (2001):Identification of 5 types of Cryptosporidium parasites in chil dren in Lima, Peru. J Infect Dis. 183:492-497. 
دراسة لتثخيص وتصنيف الطفيليات المعوية بأستخدام البلمرة التسلسلية مقارنة بالتقتيات العادية المستخدمة فى التثخيص بمدينة دمياط

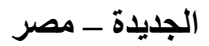

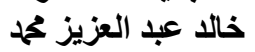

قسم الطفيلياتـ كلية الطب- جامعة الأزهر هرئ - دمياط

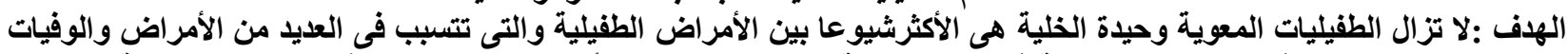

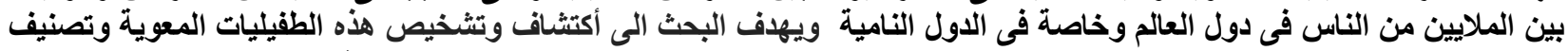

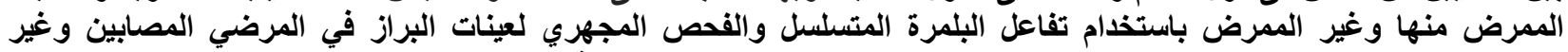
المصابين بمدينة دمياط الجديدة العيدات

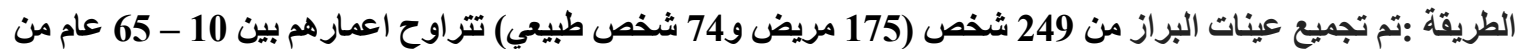

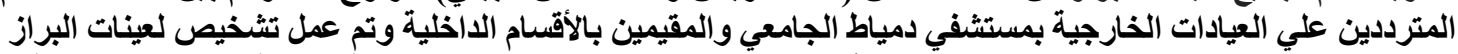

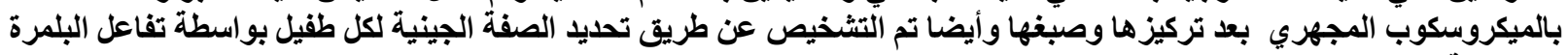
التسلسلية

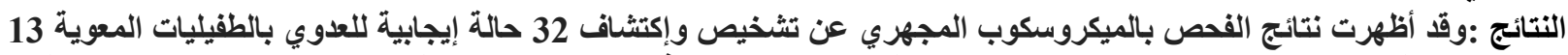

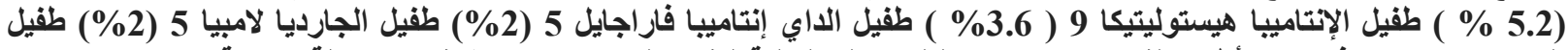

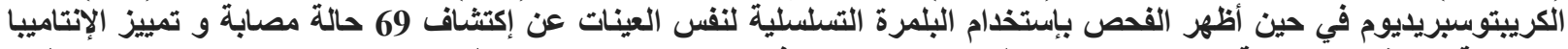

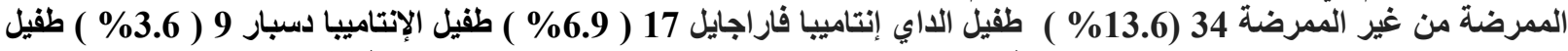

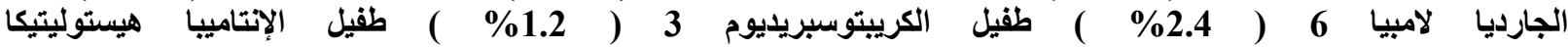

الأستنتاج :أظهرت النتائج إرتفاع معدل الإصابة بالطقيليات المعوية وحيدة الخلية بين الحالات التي شملتهم الدراسة ولا سيما بين

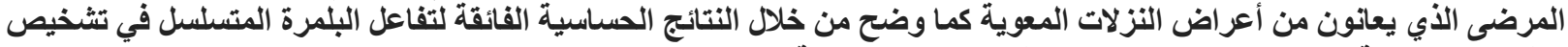

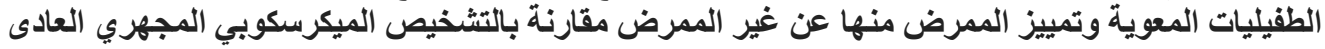

